Universidade Tecnológica Federal do Paraná - UTFPR

Campus Ponta Grossa - Paraná - Brasil

ISSN: 1981-3686 / v. 02, n. 02: p. 15-24, 2008
Revista Brasileira de Tecnologia

Agroindustrial

\title{
ELABORAÇÃO E CARACTERIZAÇÃO DO FIAMBRE DE PEIXE A PARTIR DA GURIJUBA (Arius parkeri)
}

\section{ELABORATION AND CHARACTERIZATION OF FISH TINNED FROM GURIJUBA}

(Arius parkeri)

\author{
Elen Vanessa Costa da Silva ${ }^{1}$; Gisele Freitas da Silva ${ }^{1}$; Alan José Leal do Amaral $^{2}$ \\ Mayara Elaine Borges de Santana ${ }^{3}$ \\ ${ }^{1,2,3}$ Universidade do Estado do Pará -UEPA-Belém-PA-Brasil \\ elen@uepa.br
}

\section{Resumo}

Este trabalho tem como objetivo principal, elaborar fiambre através do aproveitamento de partes comestíveis de peixes gurijuba (Arius parkeri), além de sua caracterização. Acredita-se que este processo possibilite um estágio mais desenvolvido na industrialização do pescado, justamente por envolver a aplicação de uma tecnologia não tradicional e facilmente adaptável. Foram realizadas análises físico-químicas (umidade, proteínas, cinzas, lipídeos, carboidratos), microbiológicas (Coliformes fecais, Salmonella e Staphylococcus aureus,) e sensorial (Teste de aceitação). Os resultados mostraram que o fiambre de peixe apresentou umidade: 63,87\%, proteínas: 15,18\%, cinzas: 2,73\%, lipídeos: 16,3\%, carboidratos: 1,92\% e valor calórico: 215,1 Kcal. Com relação à análise microbiológica não houve contaminação, o produto analisado encontra-se dentro dos padrões estabelecidos pela legislação vigente. Na análise sensorial apresentou aceitação de $81 \%$. Apresentou ainda um rendimento de 99,13\%, sendo considerado um produto sem restrições de comercialização.

Palavras-chave: conserva, produto cárneo, processamento.

\section{Introdução}

O Brasil apresenta um dos mais baixos índices de consumo de pescado. Este índice, dentre outros fatores, provalvemente deve-se à falta de conhecimento da importância do pescado na alimentação (MORGANTI, 1980). A oferta de produtos derivados de pescado e a diversificação na linha de produtos de origem marinha poderão incrementar o consumo deste produto, em particular 
na região sul do Brasil, onde tradicionalmente o consumo de carnes das chamadas espécies de açougue apresenta o maior índice per capita (FREITAS, 1997).

Vários fatores contribuíram para o desenvolvimento de produtos à base de carne de peixe, entre eles necessidade de carne leve; aperfeiçoamento no processamento, no armazenamento e no marketing; e aumento da demanda por produtos de preparo fácil e rápido. Em meados da década de 80, produtos elaborados com carne de peixes eram vendidos a preços competitivos e até inferiores aos elaborados com as carnes suína ou bovina, e conquistava uma faixa crescente do mercado, devido à propaganda enfatizando seu valor nutricional (GRANER, 1992).

Considerando que a demanda de produtos alimentícios será cada vez maior, principalmente para aqueles com proteína de alto valor nutricional e valor tecnológico agregado, a recuperação das proteínas de pescado, de espécies de baixo valor comercial ou dos subprodutos de sua industrialização, constitui-se numa alternativa promissora (SIMÕES, 2007). E para buscar como alternativa a carne de peixe, basta um pouco de criatividade para ter na mesa pratos baratos, saudáveis e criativos como elaboração de produtos tipo salsicha, lingüiça, fishburguer, fiambre, etc.

Este trabalho tem como objetivo principal agregar valor à matéria prima através da elaboração de fiambre utilizando partes comestíveis de peixes gurijuba (Arius parkeri), conhecendo suas características através das análises físico-quimica, microbiológica e sensorial.

\section{Material e métodos}

\subsection{Material}

- Matéria prima

Carne de pescado: Utilizou-se carne do pescado Gurijuba, adquirido no mercado local.

- Coadjuvantes

Toucinho, Envoltório, Condimentos e Aditivos (Pó Húngaro, Fixador A-80, Glutamato monossódi, Pimenta) Sal, Água e Gelo.

\subsection{Elaboração do fiambre de peixe}

A elaboração baseou-se na formulação de TERRA (1998). O início do processo ocorreu com a separação da carne e das espinhas e pele $\left(5^{\circ} \mathrm{C}\right)$. Retirou-se o couro do toucinho de suíno, e o mesmo foi cortado em pedaços pequenos. Em seguida transferiu-se a carne de peixe para o processador, posteriormente foram distribuídos, 1/3 do gelo, o sal e os demais aditivos. $\mathrm{O}$ restante 
do gelo foi adicionado gradativamente. Essa adição gradativa manteve a temperatura da carne ao redor de $5^{\circ} \mathrm{C}$ durante a trituração.

Ao perceber que a massa apresentava características de que a proteína miofibrilar estava sendo extraída, o toucinho de porco foi adicionado para favorecer as características de emulsão do produto e triturou-se até que a temperatura da emulsão atingisse $15^{\circ} \mathrm{C}$. Após a preparação da emulsão, partiu-se para o envase em forma de alumínio previamente higienizados.

O cozimento foi realizado em Banho Maria, com temperatura de $80^{\circ} \mathrm{C}$ por 30 minutos, até que a temperatura interna do fiambre atingisse 72 a $75^{\circ} \mathrm{C}$. Após a cocção, o fiambre foi resfriado em água corrente a temperatura ambiente e armazenado em temperatura de refrigeração $\left(5^{\circ} \mathrm{C}\right)$. Estas etapas de processamento e a formulação podem ser mais bem visualizadas no fluxograma da Figura 01 e na Tabela 01, respectivamente.

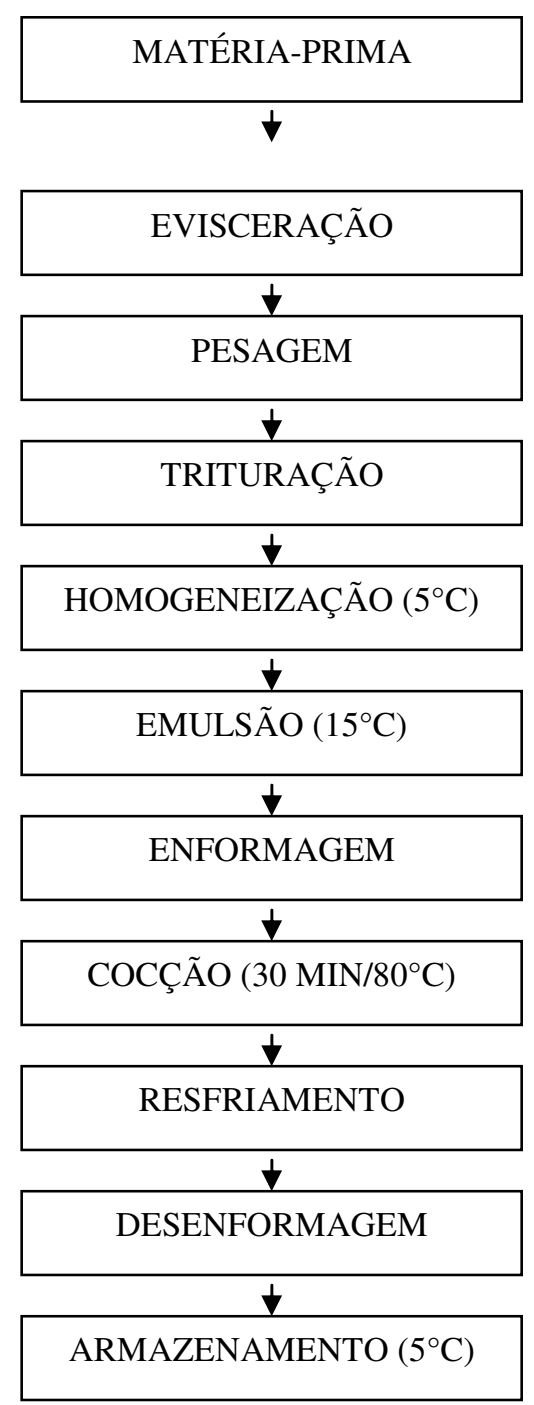

Figura 01: Fluxograma de produção do fiambre de peixe. 
Tabela 01: Formulações dos fiambres.

\begin{tabular}{lc}
\hline \hline Componentes & Fiambre de peixe $(\%)$ \\
\hline \hline Carne de peixe & 75,75 \\
Toucinho & 18,92 \\
Sal & 1,91 \\
Gelo & 2,38 \\
Krakoline & -- \\
Fixador & 0,16 \\
Pó húngaro & 0,16 \\
Pimenta moída & 0,24 \\
Glutamato monossódico & 0,48 \\
\hline \hline
\end{tabular}

\section{Análises laboratoriais}

\subsection{Análise físico-química}

As caracterizações físico-químicas foram realizadas de acordo com os métodos descritos pelo Instituto Adolfo Lutz (1985), conforme disposto abaixo:

- Umidade: Determinada utilizando estufa a $105^{\circ} \mathrm{C}$, até peso constante;

- Cinzas: Para a determinação do teor de cinzas realizou-se calcinação das amostras a $550^{\circ} \mathrm{C}$, até peso constante;

- Gordura: Conduziu-se a análise do teor de gordura com extração através de solventes (éter de petróleo), no aparelho especial para determinação de gordura;

- Proteínas: O teor de proteínas foi determinado pelo método Kjedahl, utilizando aparelho digestor macro tecnal especial;

- Carboidrato: Determinado por diferença através da Equação 1:

$$
\mathrm{E}=100-(\mathrm{A}+\mathrm{B}+\mathrm{C}+\mathrm{D}) \quad \text { Eq.1 }
$$

Onde:

A = Proteína

$\mathrm{B}=$ Gordura

$\mathrm{C}=$ Umidade

$\mathrm{D}=$ Cinzas

$\mathrm{E}=$ Carboidratos 
- Valor calórico: Determinado conforme a Equação 2:

Valor Calórico $(\mathrm{cal})=($ Proteína $\times 4)+($ Carboidrato $x 4)+($ Gordura $\times 9) \quad$ Eq.2

\subsection{Análises microbiológicas}

Os produtos obtidos (A, B, C) foram submetidos às análises de Coliformes Fecais, Coliformes Totais, Bolores e Leveduras, Contagem Padrão de Bactérias, Salmonella e Staphylococcus aureus, realizadas no Laboratório de Microbiologia do Centro de Ciências Naturais e Tecnologia da UEPA, de acordo com a metodologia descrita por Vanderzant \& Splittstoesser (1992). Os resultados foram analisados segundo BRASIL (2001).

Análise sensorial

Os testes de análise sensorial foram realizados no horário compreendido entre 9:00 e 11:00 h, com 30 provadores não treinados de ambos os sexos. Aplicou-se o Teste de Aceitação, com escala hedônica estruturada de 9 pontos, ancorada nos seus extremos, pelos termos: gostei muitíssimo (9) e desgostei muitíssimo (1) (DUTCOSKY, 1996).

\subsection{Análise de rendimento e de custo}

O calculo do rendimento foi feito através da relação entre o produto final e a quantidade inicial de matéria-prima (SANTOS, 1999).

O calculo do custo foi feito através da relação entre preço por quilo e quantidade de matériaprima utilizada na formulação.

\section{Resultados e Discussão}

Caracterização físico-química

Os resultados das análises físico-químicas do fiambre de peixe, e os resultados observados por BRASIL (2000) para carne bovina são mostrados na Tabela 02. 
Tabela 02: Resultados das análises físico-químicas do fiambre de peixe.

\begin{tabular}{ccc}
\hline \hline Determinações & Fiambre de peixe & BRASIL (2000) \\
\hline \hline Umidade (\%) & 63,87 & Max. 70 \\
Proteína (\%) & 15,18 & Min. 12 \\
Cinzas (\%) & 2,73 & --- \\
Lipídeos (\%) & 16,30 & --- \\
Carboidratos (\%) & 1,92 & Max. 10 \\
Valor calórico (Kcal) & 215 & ---- \\
\hline \hline
\end{tabular}

Segundo ROCHA (2004) o peixe é um alimento de origem animal muito rico em proteínas, vitaminas, sais minerais e de fácil digestão. É considerado um dos alimentos mais completos para o homem pelo seu valor nutritivo alem de conter gorduras não-saturadas o que ajuda a reduzir os níveis de colesterol.

O resultado obtido para umidade $(63,87 \%)$ esta dentro dos padrões observados na legislação, que estabelece valor máximo de $70 \%$ para pescado (BRASIL, 2000). A água é o constituinte que aparece em maior proporção na carne de pescados em torno de $75-80 \%$ da carne proporcionando um produto com alto teor de umidade (GEROMEL \& FORSTER, 1982).

O teor de proteínas obtido no fiambre $(15,18 \%)$ foi considerado satisfatório e acima do limite da legislação (min. 12\%). Ressalta-se que o produto final pode ser considerado essencial na dieta alimentar, por conter nutriente de qualidades como os aminoácidos essenciais (CAETANO, 1973).

Na legislação para fiambre (BRASIL, 2000) não existe padrão para o teor de cinzas, no entanto foi encontrado no produto o valor de $2,73 \%$. Na composição da carne de peixe, os minerais (cálcio, ferro, fósforo, cobre e magnésio) têm proporção idêntica à de outros tipos de carne, em torno de 0,8 a $2 \%$ (COSTA, 2006). Outro fator que influenciou no teor de minerais foram os componentes da formulação como sal, aditivos (glutamato, krakoline, fixador e pó húngaro) e condimentos (pimenta do reino).

Também não existe padrão para lipídeo na legislação (BRASIL, 2000), no entanto, foi realizada a análise e encontrado valor de $16,30 \%$. Em uma pesquisa realizada por SILVA \& SILVA (2007) mostrou que a gurijuba foi uma das espécies que apresentou maior teor em lipídeos.

Para carboidratos obteve-se 1,92\%, valor dentro do limite da legislação para fiambre (BRASIL, 2000). Os pescados geralmente apresentam um teor muito baixo de carboidratos em sua carne, inferior a $1 \%$ (GEROMEL \& FORSTER, 1982).

Análise microbiológica 
Os resultados das análises microbiológicas do fiambre de peixe para contagem de Coliformes fecais a $45^{\circ} \mathrm{C}$, Salmonella e Staphylococcus aureus estão apresentados na Tabela 03, bem como o padrão da legislação BRASIL (2001).

Tabela 03: Resultado das análises microbiológicas do fiambre de peixe.

\begin{tabular}{cccc}
\hline \hline Produto & $\begin{array}{c}\text { Coliformes Fecais } \\
\mathrm{a} 45^{\circ} \mathrm{C}(\mathrm{NMP} / \mathrm{g})\end{array}$ & $\begin{array}{c}\text { Salmonella } \\
/ 25 \mathrm{~g}\end{array}$ & $\begin{array}{c}\text { Staphylococcus aureus U } \\
\mathrm{g}\end{array}$ \\
\hline \hline Fiambre de peixe & $<3$ & Ausência & $<1,0 \times 10^{1}$ \\
Padrão (BRASIL 2001) & $10^{3}$ & Ausência & $3 \times 10^{3}$ \\
\hline \hline
\end{tabular}

Os resultados obtidos nas analises microbiológicas estão de acordo com os padrões legais vigentes, BRASIL (2001), apresentados na Tabela 03.

A manipulação incorreta do pescado prejudica seu aspecto e reduz sua conservabilidade, uma vez que os efeitos não são imediatamente aparentes. A eficiência da lavagem (sistema e qualidade água, cloro, etc.), gelo de boa qualidade par o armazenamento, a triagem doa exemplares deteriorados ou danificados e tratamento dado durante a fase de processamento, também influenciam o nível de excelência de qualidade do produto final (RUIVO, 1988).

Análise sensorial

Os resultados da análise sensorial (teste de aceitação), com 35 provadores, indicaram as seguintes aceitações, do fiambre de peixe, como mostra a Tabela 10.

Tabela 04: Resultado da análise sensorial do fiambre de peixe.

\begin{tabular}{cc}
\hline \hline Produto & Aceitabilidade (\%) \\
\hline \hline Fiambre de peixe & $\mathbf{8 1}$ \\
\hline \hline
\end{tabular}

Nesta avaliação, o produto (fiambre de peixe) foi servido cozido e verificou-se na Tabela 04 que a formulação obteve aceitação (81\%) situada na Escala Hedônica como: gostei muito. Análise do rendimento e de custo

O resultado da análise de rendimento do produto encontra-se na Tabela 05.

Tabela 05: Resultado da análise de rendimento do fiambre de peixe.

\begin{tabular}{cc}
\hline \hline Produto & Rendimento \\
\hline \hline Fiambre de peixe & 99,13 \\
\hline \hline
\end{tabular}


De acordo com os resultados encontrados, o fiambre de peixe apresentou rendimento excelente, de 99,13\%, haja vista que teve perda apenas de água do produto através do cozimento mostrando ser um produto viável para produção industrial pelo seu ótimo rendimento.

O resultado das análises de custo do produto encontra-se na Tabela 06.

Tabela 06: Resultado da análise de custo do fiambre de peixe.

\begin{tabular}{lccc}
\hline \hline Componentes & Quantidades/ (kg) & Preço por kg & $\mathrm{R} \$$ \\
\hline \hline Carne de peixe & 757,5 & 6,00 & 4,55 \\
Toucinho & 189,2 & 3,00 & 0,57 \\
Sal & 19,1 & 0,40 & 0,05 \\
Gelo & 32,8 & 0,50 & 0,01 \\
Fixador & 1,6 & 6,00 & 0,01 \\
Pó húngaro & 1,6 & 6,00 & 0,01 \\
Pimenta moída & 2,4 & 12,50 & 0,03 \\
Glutamato monossódico & 4,8 & 0,65 & 0,01 \\
TOTAL & 1.000 & --- & 5,25 \\
\hline \hline
\end{tabular}

O custo foi de 5,25 reais para cada quilo de fiambre mostrando ser um produto de baixíssimo custo em comparação com produtos similares, possibilitando assim uma fácil aquisição desse produto.

\section{Conclusão}

Os resultados mostraram que o fiambre de peixe apresentou valor protéico $(15,18 \%)$ superior ao limite da legislação (min 12\%) sendo considerado um alimento nutritivo. Nas análises microbiológicas apresentou ausência de contaminastes, atestando a eficiência e higiene na elaboração do produto. Na avaliação sensorial o produto foi bastante apreciado pelos provadores obtendo $81 \%$ de aceitabilidade. O produto apresentou rendimento satisfatório de 99,13\%, sendo viável sua produção industrial. O custo foi de 5,25 reais para cada quilo de fiambre mostrando ser um produto de baixíssimo custo.

Com base em todos os dados a cima citados pode-se avaliar o fiambre de peixe como um produto prático, devido ser um enlatado de fácil preparo. Rentável, ao que diz respeito à sua produção. Nutritivo, por ter como matéria prima o peixe é um alimento de fácil digestão e considerado fonte de vários nutrientes, entre eles o Omega 3 que é de extrema importância à saúde, além de estimular o consumo de peixe, que é um alimento pouco consumido quando comparado com as carnes vermelhas. 


\begin{abstract}
In Order to note the population necessity in consuming of nutritious, functional and pratical foods has been the initiative to make the fish tinned. Where the fish tinned is a meat industrialized product according to legislation. This product is obtained from several species of animals, butcher and edible offal, with addition of ingredients and it is submitted in thermal process appropriated. This work aims to prepare the tinned though of the edible parts of fish gurijuba (Arius parkeri) and it's characterization. It's believed that this process provides a strange futher developed in the fish industrialized because it's involve the application about nontraditional and technology adaptable. Physiochemical (moisture, protein, ash, lipids, carbohydrates) and microbiological (Coliformes Fecais, Salmonella and Staphilococcus aureus) were carried out. According to results presents in fish tinned: humidity $(63,87 \%)$, protein $(15,18 \%)$, ash $(2,73 \%)$, lipids $(215,1 \mathrm{kcal})$. After microbiological analysis, it was observed that the product was proper for human consumption, because it is inside of the patterns microbiological effective. The sensory evaluation showed $81 \%$ of acceptance. It is presented 99,13\% of Yield and it's considered an unrestricted product for marketing.
\end{abstract}

Key-words: canned, meat product, processing.

\title{
Referências
}

BRASIL. Ministério da Agricultura e do Abastecimento; Instrução Normativa no ${ }^{\circ}$ 20, de 31 de julho de 2000 - Regulamento Técnico para Fixação de Identidade e Qualidade de Fiambre. Diário Oficial da União, Brasília, DF, 2000.

BRASIL. Ministério da Saúde. Agência Nacional de Vigilância Sanitária. Resolução-RDC, n 12, de 2001. Aprova o Regulamento Técnico Sobre Padrões Microbiológicos Para Alimentos. Diário Oficial da União, Brasília, DF, 10 jan. 2001.

COSTA, C.; $\quad$ Saúde $\quad$ Símbolo $\quad$ Nutritivo; $\quad 2006 . \quad$ Disponível $<$ http://alimentoseguro.locaweb.com.br/noticias24.asp?tipo_tabela=noticias\&id=24\&categoria=saude $>$. Acessado agosto de 2007.

DUTCOSKY, S. D. Análise Sensorial de Alimentos. Curitiba: Champagnat, 1996. 123p.

FREITAS, C. M. K. H. de, Embutidos de Peixe: Uma proposta para o Aproveitamento Tecnológico ao Produto da Pesca Paraense. Belém - PA. 1997.

Geromel, E. J. \& FORSTER, R. J. Princípios Fundamentais em Tecnologia de Pescado. São Paulo, Secretaria da Indústria, Comercio, Ciência e Tecnologia. Coordenadoria e Comercio, 1982. 127p.

GRANER; M., Elaboração de Fiambres com as Carnes Branca e Escura de Frango, 1992. Disponível: <http://www.scielo.br/pdf/sa/v49nspe/22.pdf>. Acesso agosto de 2007.

MORGanti, R. Tendências do Mercado Para o Fornecimento de Carne a Industria e Exportação. Instituto de Tecnologia de Carne - ITAL; Centro de Tecnologia de Carne; Curso de Tecnologia de Carne, 1980.

NORMAS ANAliticAs DO InStituto ADOLFO LUTZ. Métodos Físicos e Químicos Para Analise de Alimentos. Vol. 1. São Paulo - SP, 1985. 
ROCHA, R. Processamento de Pescado. CENTEC - Cardenos Tecnológicos. Fortaleza - CE, 2004.

RUIVO, U.E. A Analise Sensorial na Avaliação da Qualidade de Pescado in: SEMINARIO SOBRE CONTROLE DE QUALIDADE NA INDÚSTRIA DE PESCADO, 1988, Santos. Trabalhos Apresentados, Santos: Leopoldinum, Loyola, 1988. 303 p.p.69-80.

SANTOS, A. L. C. Elaboração e Caracterização de Salsicha Tipo “Hot Dog” Bubalina e Bovina. 1999. Monografia (Especialização em Tecnologia de Alimentos) - Departamento de Engenharia Química, Universidade Federal do Pará, 1999.

SILVA; I. Q., SILVA; L. H. M. Caracterização do Perfil de Ácidos Graxos de Seis Espécies de Peixes Amazônicos. Volume 06 NNo $^{\circ} 01$ / Maio - Setembro de 2007. Disponível

SIMÕES, D.R.S., et al. Hambúrgueres Formulados com Base Protéica de Pescado. Disponível http://www.scielo.br/scielo. Acessado agosto de 2007.

TERRA, N. N. Apontamentos Sobre Tecnologia de Carnes. São Leopoldo: UNISINOS, 1998.

VANDERZANT, C.; SPLITTSTOESSER, D. F. Compendium of Methods for Microbiological Examination of Foods. 3. ed. Washington, DC: American Public Health Association, 1992, 914p.

Primeiro autor: Elen Vanessa Costa da Silva

Filiação institucional: Universidade do Estado do Pará

Departamento: Tecnologia de Alimentos

Função ou cargo ocupado: Professora Assistente 40h

Endereço completo para correspondência (bairro, cidade, estado, país e CEP): conjunto Médici I,

Tv. Benevides, 105. Bairro: Marambaia, Belém, PA, Brasil, CEP 66620460

Telefones para contato: (91) 81140062; (91) 32316019

e-mail:elen.vanessa@bol.com.br ou elen@uepa.br 